\title{
Improved Performances of a Fluidized Bed Photoreactor by a Microscale Illumination System
}

\author{
Paolo Ciambelli, ${ }^{1,2}$ Diana Sannino,,${ }^{1,2}$ Vincenzo Palma, ${ }^{1}$ Vincenzo Vaiano, ${ }^{1}$ \\ and Roberto S. Mazzei ${ }^{1}$ \\ ${ }^{1}$ Department of Chemical and Food Engineering, University of Salerno, Via Ponte Don Melillo, 84084 Fisciano (Salerno), Italy \\ ${ }^{2}$ NANO_MATES, Research Centre for Nanomaterials and Nanotechnology at Salerno University, University of Salerno, \\ Via Ponte Don Melillo, 84084 Fisciano (Salerno), Italy
}

Correspondence should be addressed to Diana Sannino, dsannino@unisa.it

Received 31 March 2009; Revised 17 July 2009; Accepted 2 September 2009

Recommended by Mohamed Sabry Abdel-Mottaleb

The performances of a gas-solid two-dimensional fluidized bed reactor in photocatalytic selective oxidation reactions, irradiated with traditional UV lamps or with a microscale illumination system based on UV emitting diodes (UVA-LEDs), have been compared. In the photocatalytic oxidative dehydrogenation of cyclohexane to benzene on $\mathrm{MoO}_{\mathrm{x}} / \mathrm{TiO}_{2}-\mathrm{Al}_{2} \mathrm{O}_{3}$ catalyst the use of UVA-LEDs modules allowed to achieve a cyclohexane conversion and benzene yield higher than those obtained with traditional UV lamps. The better performances with UVA-LEDs are due to the UVA-LEDs small dimensions and small-angle emittance, which allow photons beam be directed towards the photoreactor windows, reducing the dispersion outside of photoreactor or the optical path length. As a consequence, the effectively illuminated mass of catalyst is greater. We have found that this illumination system is efficient for photo-oxidative dehydrogenation of cyclohexane to cyclohexene on sulphated $\mathrm{MoO}_{\mathrm{x}} / \gamma-\mathrm{Al}_{2} \mathrm{O}_{3}$ and ethanol to acetaldehyde on $\mathrm{VO}_{\mathrm{x}} / \mathrm{TiO}_{2}$.

Copyright ( $) 2009$ Paolo Ciambelli et al. This is an open access article distributed under the Creative Commons Attribution License, which permits unrestricted use, distribution, and reproduction in any medium, provided the original work is properly cited.

\section{Introduction}

Heterogeneous photocatalysis is the subject of an increasing interest during the last twenty years. A challenging research topic is the synthesis and production of chemicals by partial photo-oxidation reactions by molecular oxygen under mild conditions [1]. In this context photocatalysis can lead to more sustainable processes by increasing both reactivity and selectivity towards the desired products because of mild operating conditions, that are, low temperature and pressure [2]. However, a competitive full-scale photocatalytic oxidation process in industrial application requires overcoming photons and mass transfer limitations in the photocatalytic reactors [2]. With reference to mass transfer limitations a large number of novel solutions have been developed for the photoreactors, including spinning disc reactors [3,4], monolith photoreactors [5], and microreactors [6]. Fluidized bed photoreactors are well known in enhancing mass transfer kinetics. Moreover, they provide easy temperature control and good contacting between reactants and photocatalysts with respect to fixed bed photoreactors [7-11].

Regarding photons transfer, microscale illumination systems are a promising solution [2]. This type of illumination is realized mainly by irradiating the photoreactor with UV emitting diodes (UVA-LEDs) device [12-14]. LEDs are replacing traditional UV lamps in many applications, owing to the much higher efficiency in light-electricity conversion, since the light emission by LEDs is induced by the recombination of electrons and holes excess [15]. Further advantages of LEDs derive from the small dimensions, robustness, and the long lasting (hundred thousands of hours compared to thousands of hours in the case of classical lamps) [2].

The use of microscale illumination in photoreactors can provide both a large catalyst surface area per unit of reactor volume and high illumination efficiency, also profiting of the small angle of emittance of the LEDs [2].

In this work, the performances of a gas-solid twodimensional fluidized bed reactor with traditional UV lamps 
TABLE 1: List of the photocatalysts and their characteristics

\begin{tabular}{|c|c|c|c|c|c|c|}
\hline Catalyst & Support & $\mathrm{V}_{2} \mathrm{O}_{5} \mathrm{wt} \%$ & $\mathrm{MoO}_{3} \mathrm{wt} \%$ & $\mathrm{SO}_{4} \mathrm{wt} \%$ & $\mathrm{SSA} \mathrm{m}^{2} / \mathrm{g}$ & Band gap energy eV \\
\hline $8 \mathrm{Mo} 2 \mathrm{~S}$ & $\gamma-\mathrm{Al}_{2} \mathrm{O}_{3}$ & 0 & 8 & 2.6 & 147 & 3.4 \\
\hline $5 \mathrm{~V}$ & $\mathrm{TiO}_{2}$ & 5 & 0 & 0.2 & 74 & 2.5 \\
\hline 10MoPCAl & $\mathrm{TiO}_{2}-\mathrm{Al}_{2} \mathrm{O}_{3}$ & 0 & 10 & 0.8 & 148 & 3.3 \\
\hline
\end{tabular}

and with a microscale illumination system based on UV emitting diodes (UVA-LEDs) have been compared for the oxidative dehydrogenation of cyclohexane to benzene as probe reaction. The effectiveness of the device in photocatalytic oxidative dehydrogenation both in cyclohexane to cyclohexene and in ethanol to acetaldehyde was also evaluated.

\section{Experimental}

2.1. Catalysts Preparation. The photocatalysts formulation investigated in this work (Table 1) is the result of previous optimization studies on photo-oxidative dehydrogenation of cyclohexane to benzene [16] or cyclohexene $[9,10]$, and of ethanol to acetaldehyde [17].

The $8 \mathrm{Mo} 2 \mathrm{~S}$ photocatalyst was prepared by wet impregnation of $\mathrm{Al}_{2} \mathrm{O}_{3}$ (Puralox SBA 150, SASOL, $144 \mathrm{~m}^{2} / \mathrm{g}$ ) with aqueous solution of ammonium heptamolybdate $\left(\mathrm{NH}_{4}\right)_{6} \mathrm{Mo}_{7} \mathrm{O}_{24} \cdot 4 \mathrm{H}_{2} \mathrm{O}$. Powder samples were dried at $120^{\circ} \mathrm{C}$ for 12 hours and calcined in air at $500^{\circ} \mathrm{C}$ for 3 hours. A successive wet impregnation with aqueous solution of ammonium sulphate was performed to obtain sulphated catalyst samples $[9,10]$.

The $\mathrm{TiO}_{2}-\mathrm{Al}_{2} \mathrm{O}_{3}$ formed support was prepared by dispersing the parent titania (PC100, $87 \mathrm{~m}^{2} / \mathrm{g}, 20 \mathrm{~nm}$ crystallites average size, provided by Millenium Inorganic Chemicals) powder in a boehmite sol (10 wt \% of Condea Pural in bydistilled water, $\mathrm{pH}<2$ by $\left.\mathrm{HNO}_{3}\right)$. The sol was gelled by slight heating until it was too viscous to stir. The gel was thus dried at $120^{\circ} \mathrm{C}$ for 3 hours and calcined at $500^{\circ} \mathrm{C}$ for 2 hours. After calcination the solid was crushed and sieved to $50-90 \mu \mathrm{m}$ size. Finally, the solid (30 wt $\% \mathrm{Al}_{2} \mathrm{O}_{3}$ ) was impregnated with $\left(\mathrm{NH}_{4}\right)_{6} \mathrm{Mo}_{7} \mathrm{O}_{24}$ solution, dried and calcined at $400^{\circ} \mathrm{C}[16]$ to have $10 \mathrm{MoPCAl}$ sample.

The $5 \mathrm{~V}$ catalyst was prepared by wet impregnation method. Anatase titania sample (PC105, $86 \mathrm{~m}^{2} / \mathrm{g}, 23 \mathrm{~nm}$ crystallites average size, provided by Millenium Inorganic Chemicals) was added to an aqueous solution of $\mathrm{NH}_{4} \mathrm{VO}_{3}$ and dried at $120^{\circ} \mathrm{C}$ until achieving a dense paste. The paste was calcined in static air heating up to $400^{\circ} \mathrm{C}$ at $10^{\circ} \mathrm{C} / \mathrm{min}$ heating rate, then kept isotherm for 3 hours to get the final catalyst [17].

The specific surface area of calcined samples was evaluated by $\mathrm{N}_{2}$ adsorption isotherm at $-196^{\circ} \mathrm{C}$ with a Costech Sorptometer 1040 , after pretreatment at $180^{\circ} \mathrm{C}$ for 2 hours in He flow (99.9990\%).

UV-Vis reflectance spectra of powder bare catalysts were recorded by a Perkin Elmer spectrophotometer Lambda 35 with an RSA-PE-20 reflectance spectroscopy accessory (Labsphere Inc., North Sutton, NH). An $8^{\circ}$ sample positioning holder was used to obtain total reflectance spectra with reference to a calibrated standard SRS-010-99 (Labsphere Inc., North Sutton, NH). The reflectance data were reported as the $F\left(R_{\infty}\right)$ value from Kubelka-Munk theory versus the wavelength. Band gap determinations were made by plotting $\left[\mathrm{F}\left(\mathrm{R}_{\infty}\right)^{*} \mathrm{~h} \nu\right]^{2}$ versus $\mathrm{h} \nu(\mathrm{eV})$ as reported in $[9,10]$.

2.2. Photoreactor and Photocatalytic Tests. A two-dimensional fluidized bed photoreactor was designed in order to improve both exposure of the catalysts to light irradiation and contact between reactants and catalysts [18]. The reactor is a two-dimensional fluidized bed system with $40 \mathrm{~mm}$ $\times 10 \mathrm{~mm}$ cross section, $230 \mathrm{~mm}$ height, pyrex-glass walls ( $2 \mathrm{~mm}$ thickness), and a bronze filter (mean pores size $5 \mu \mathrm{m})$ to provide uniform distribution of fed gas $[9,18]$. In the first configuration the reactor was illuminated by two UV lamps (EYE MERCURY LAMP, $125 \mathrm{~W}$ ) with spectrum emission centred at $365 \mathrm{~nm}$, in a dark box (Figure 1(a)). The light intensity entering at the reactor walls, measured by an UVA meter, was $30 \mathrm{~mW} / \mathrm{cm}^{2}$. The reaction temperature was controlled by a PID temperature controller connected to a heating system positioned at the external of the reactor, into the dark box surrounding it (Figure 1(b)). In the second configuration the same fluidized bed reactor was irradiated by two or four UVA-LEDs modules positioned in front of the Pyrex windows.

In Figure 2 an overall view and a schematic picture of the fluidized bed photoreactor equipped with UVA-LEDs device are shown. The reactor is also equipped with an internal electrical heater, immersed within the catalytic bed to control the reaction temperature (Figure 2(a)), avoiding the use of external screens.

Each UVA-LED module consists of 20 pieces of UVALEDs, emitting at $365 \mathrm{~nm}$ with a band width of about $38 \mathrm{~nm}$. The modules (Figure 3(a)) were assembled and adapted to the fluidized bed photoreactor windows in the best way to obtain the maximum reactor surface illumination.

A cooling system (Figure 3(b)) was designed with CAD software and manufactured by using a rapid prototyping technique. In front of the cooling box, a perforated grid, designed to contain one UVA-LED in each hole of the grid, was inserted. The cooling fluid was compressed air injected at a pressure of about 5 bars. This device (Figure 3(b)) ensures a perfect cooling of each UVA-LEDs module, whose operating temperature should not exceed $75-80^{\circ} \mathrm{C}$.

The use of four UVA-LEDs modules resulted in a larger irradiated window allowing to load a catalysts weight doubled with respect to two UVA-LEDs modules. An electrical control system connected to UVA-LEDs allows to control the light intensity incident to the external walls of the photoreactor. The light intensity was varied in the range 30$124 \mathrm{~mW} / \mathrm{cm}^{2}$. 


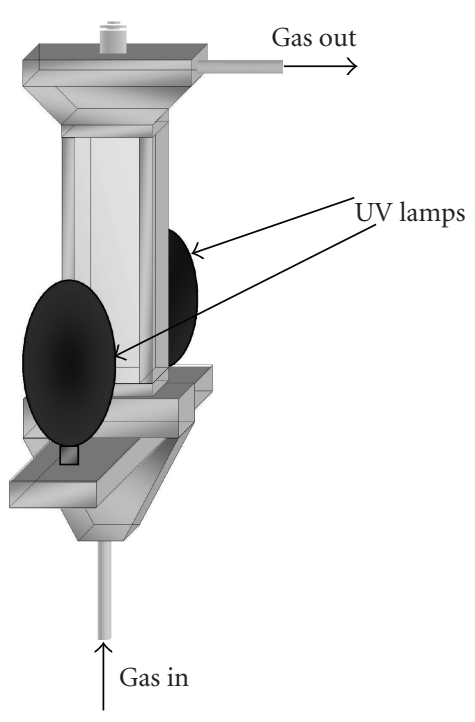

(a)

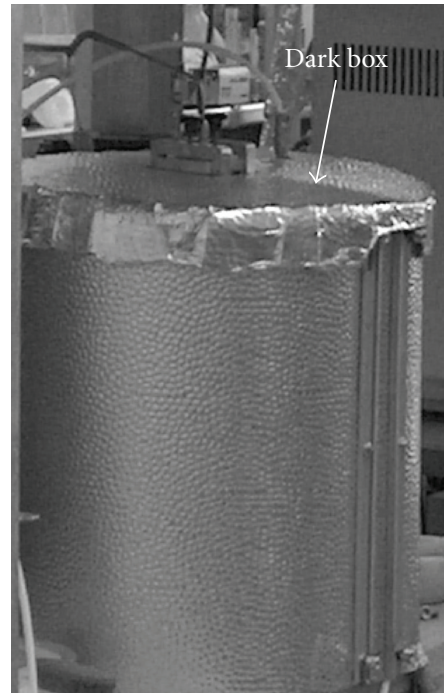

(b)

FIGURE 1: (a) Schematic picture of the fluidized bed photoreactor with UV lamps and (b) surrounded by dark box.

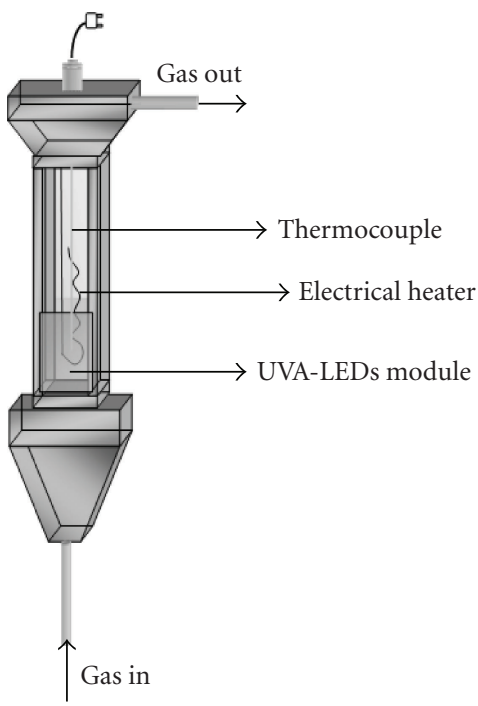

(a)

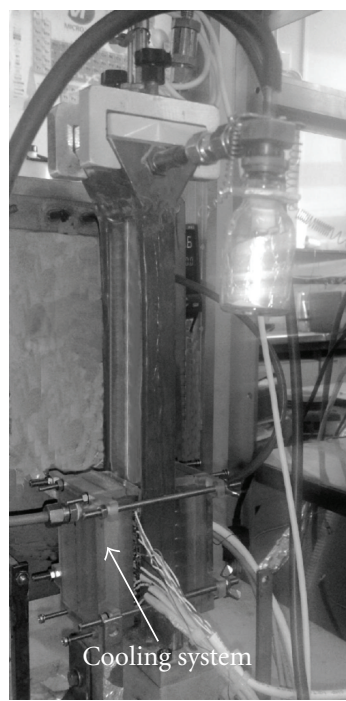

(b)

FIgURE 2: Fluidized bed photoreactor with UVA-LEDs device.

Photocatalytic activity tests were performed with the laboratory apparatus shown in Figure 4. Hydrocarbons and water were vaporized by two temperature controlled saturators. The gas flow rates were measured and regulated by mass flow controllers (Brooks Instrument). Concentrations of inlet reactants and outlet products were measured by an online quadrupole mass detector (Trace MS, ThermoElectron) and a continuous $\mathrm{CO}-\mathrm{CO}_{2}$ NDIR analyzer (Uras 10, Hartmann \& Braun).

\section{Results and Discussion}

Typical photocatalytic test started feeding the gas reacting mixture to the photoreactor at reaction temperature in dark.
After complete adsorption of reactant on the catalyst surface corresponding to the restoring of initial inlet concentration, UV sources were switched on. Without UV irradiation no reaction products were observed either during the hydrocarbon dark adsorption or after hydrocarbon adsorption equilibrium was reached.

\subsection{Photocatalytic Oxidative Dehydrogenation of Cyclohexane} to Benzene. Photocatalytic oxidative dehydrogenation of cyclohexane to benzene was carried out on 10MoPCAl catalyst feeding 830 (stp) $\mathrm{cm}^{3} / \mathrm{min}$ nitrogen stream containing 0.1 vol. \% cyclohexane, with oxygen/cyclohexane and water/cyclohexane ratio equal to 1.5 and 1.6, respectively. The reaction temperature was set at $120^{\circ} \mathrm{C}$. In Figure 5 


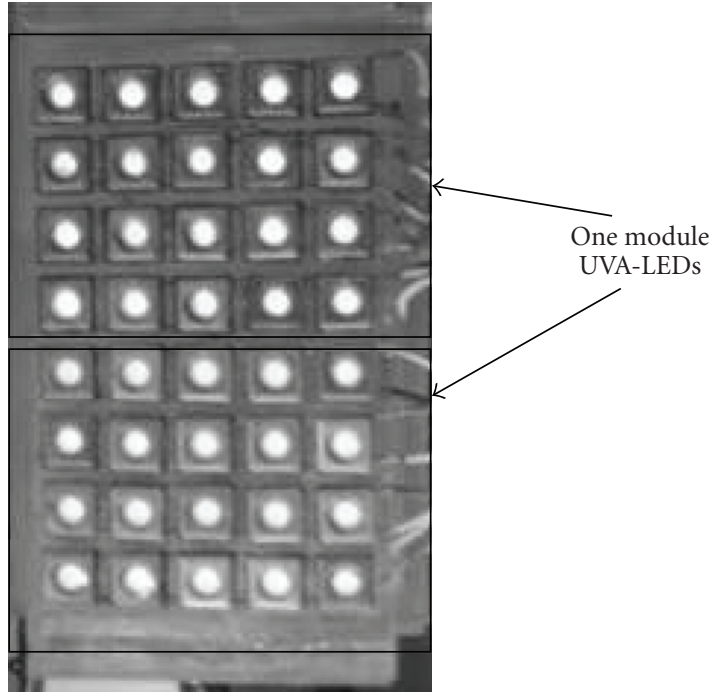

(a)

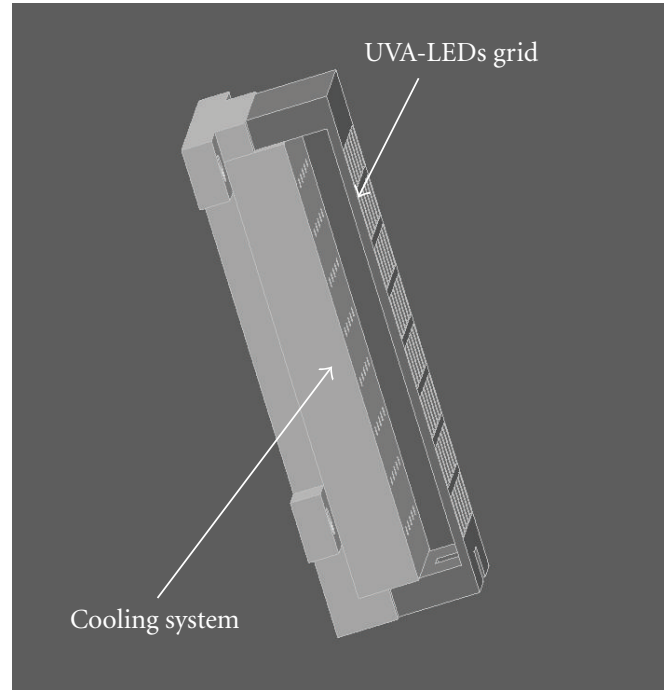

(b)

FIgURE 3: (a) UVA LEDs modules, inside the black rectangles, and (b) UVA-LEDs cooling system.

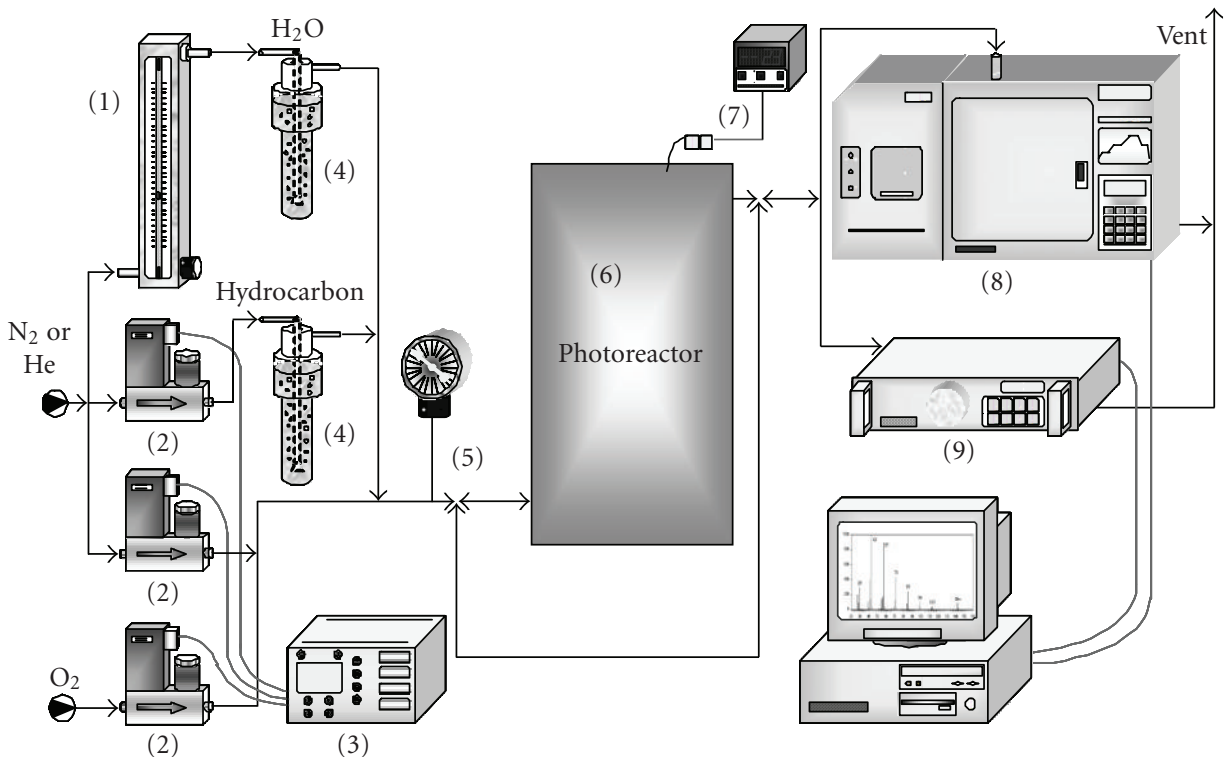

Experimental apparatus:
(1) Rotameter
(6) Photoreactor
(2) Mass flow controllers
(3) MFC control unit
(7) Thermocouple
(8) MS
(5) Manometer
(9) $\mathrm{CO}-\mathrm{CO}_{2}$ analyzer

FIGURE 4: Laboratory apparatus for photocatalytic tests.

cyclohexane conversion $(X)$ and benzene production $(P)$ are compared by using UVA-LEDs or UV lamps. It is observed that by using two UVA-LEDs modules (catalyst weight: $14 \mathrm{~g}$ ), the cyclohexane conversion and benzene concentration were, respectively, $11 \%$ and $108 \mathrm{ppm}$, while by using UV lamps (catalyst weight: $14 \mathrm{~g}$ ) the values were $6 \%$ and $58 \mathrm{ppm}$. This result indicates that UVA-LEDs have better performances in terms of catalyst illumination due to the special geometry that hinders photons dispersion. As a consequence, the effectively illuminated mass of catalyst is larger. With four UVA-LEDs modules (catalyst weight: $28 \mathrm{~g}$ ) the benzene concentration was higher $(217 \mathrm{ppm})$, the cyclohexane conversion reaching $22 \%$. In all cases the selectivity to benzene was higher than $99 \%$. 
TABLE 2: Apparent quantum yield for different illumination systems; T: two UVA-LEDs modules; F: four UVA-LEDs modules.

\begin{tabular}{lccccc}
\hline UV source & $\begin{array}{c}\text { Cyclohexane } \\
\text { conversion \% }\end{array}$ & $\begin{array}{c}\text { Catalyst } \\
\text { weight g }\end{array}$ & $\begin{array}{c}\text { Incident light } \\
\text { intensity mW/cm }\end{array}$ & $\begin{array}{c}\text { Irradiated } \\
\text { window cm }{ }^{2}\end{array}$ & $\begin{array}{c}\text { Apparent quantum } \\
\text { yield \% }\end{array}$ \\
\hline UV lamps & 6 & 14 & 30 & 92 & 0.44 \\
T & 11 & 14 & 30 & 40 & 1.86 \\
F & 22 & 28 & 30 & 80 & 1.86 \\
\hline
\end{tabular}

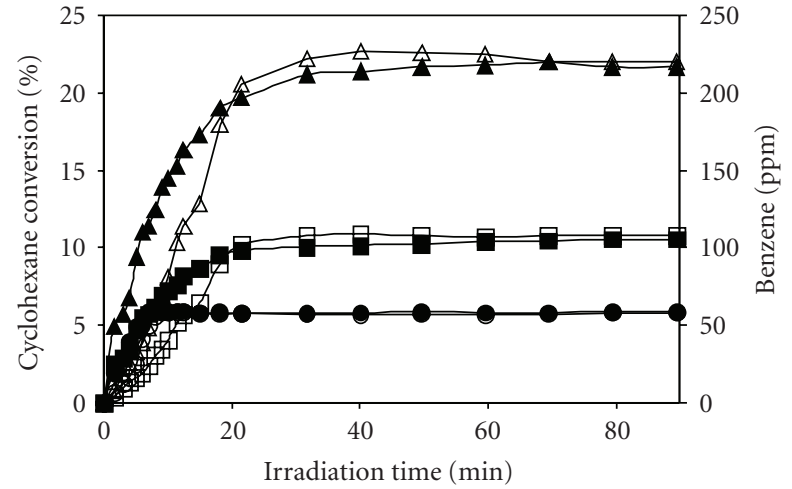

$$
\begin{array}{ll}
\multimap X \text { (UV lamps) } & -X \text { (two modules UVA-LEDs) } \\
\text { ๑ } X \text { (four modules UVA-LEDs) } & -P \text { (UV lamps) } \\
\triangle P \text { (four modules UVA-LEDs) } & \square P \text { (two modules UVA-LEDs) }
\end{array}
$$

Figure 5: Cyclohexane conversion $(X)$ and benzene concentration $(P)$ as a function of irradiation time; reaction temperature: $120^{\circ} \mathrm{C}$; light intensity: $30 \mathrm{~mW} / \mathrm{cm}^{2}$; catalyst: $10 \mathrm{MoPCAl}$.

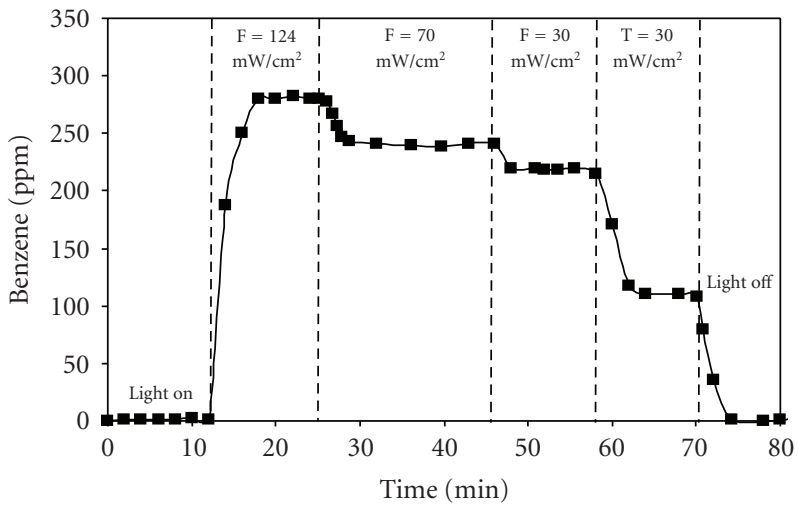

FIGURE 6: Benzene concentration as function of run time and light intensity; catalyst: 10MoPCAl; catalyst weight: 28 g; reaction temperature: $120^{\circ} \mathrm{C}$; T: two UVA-LEDs modules; F: four UVA-LEDs modules.

The apparent quantum yield, calculated as the ratio between the number of cyclohexane molecules reacted per second and the number of photons entering the reactor per second, is reported in Table 2.

It is evident that the apparent quantum yield with UVALEDs is fourfold that obtained with UV lamps, clearly indicating that process limitations are due to photon transfer. The apparent quantum yield is similar by using two and four UVA-LEDs modules, as expected since the amount of incident photons per gram of photocatalyst is the same. This comparison evidences the better performances of UVA-LEDs, due to their small dimensions and small-angle emittance, which allow photons beam be directed towards the photoreactor windows, limiting their dispersion outside of photoreactor or the length of the optical path.

To assess the effect of light intensity the experiments were performed ranging between 0 and $124 \mathrm{~mW} / \mathrm{cm}^{2}$ and with different number of UVA-LEDs modules. The cyclohexane consumption rate grows with light intensity (not reported). The results are plotted in Figure 6 in terms of benzene concentration.

It is worthwhile to note that benzene did not form in the absence of light, while its outlet concentration grew up to $280 \mathrm{ppm}$ with a light intensity of $124 \mathrm{~mW} / \mathrm{cm}^{2}$ and catalyst weight of $28 \mathrm{~g}$. It is evident that the benzene concentration decreases by decreasing the light intensity and that, at the same light intensity value $\left(30 \mathrm{~mW} / \mathrm{cm}^{2}\right)$, it was two times higher with four modules of UVA-LEDs compared to two UVA-LEDs modules illumination.

3.2. Photocatalytic Oxidative Dehydrogenation of Cyclohexane to Cyclohexene. In photocatalytic oxidative dehydrogenation of cyclohexane to cyclohexene the best condition for catalyst fluidization was obtained mixing 7 or $14 \mathrm{~g}$ of $8 \mathrm{Mo} 2 \mathrm{~S}$ catalyst with 16 or $32 \mathrm{~g}$ of $\alpha-\mathrm{Al}_{2} \mathrm{O}_{3}$, respectively. The operating conditions for photocatalytic oxidative dehydrogenation of cyclohexane to cyclohexene were the same as those used for cyclohexane oxidative dehydrogenation to benzene. The incident light intensity was $90 \mathrm{~mW} / \mathrm{cm}^{2}$. The photocatalyst allowed $100 \%$ conversion of cyclohexane to cyclohexene, without formation of benzene and $\mathrm{CO}_{2}$ as by-products $[9$, 10].

Cyclohexene was the only product detected in the gas phase; it was formed simultaneously to cyclohexane conversion after the UV irradiation was switched on (Figure 7). Cyclohexene outlet concentration reached the highest value (110 ppm after 40 minutes) with four UVA-LEDs modules and $14 \mathrm{~g}$ catalyst weight, while by using two UVA-LEDs modules and $7 \mathrm{~g}$ catalyst weight it was smaller (about $70 \mathrm{ppm}$ ) (Figure 7).

3.3. Photocatalytic Oxidative Dehydrogenation of Ethanol to Acetaldehyde. Photocatalytic oxidative dehydrogenation of ethanol to acetaldehyde was carried out on $5 \mathrm{~V}$ catalyst [17], feeding $830(\mathrm{stp}) \mathrm{cm}^{3} / \mathrm{min}$ He stream containing 0.2 or 1 vol. \% ethanol with oxygen/ethanol ratio equal to 2; reaction temperature and pressure were, respectively, $100^{\circ} \mathrm{C}$ and $1 \mathrm{~atm}$. The incident light intensity was $90 \mathrm{~mW} / \mathrm{cm}^{2}$. 
TABLE 3: Influence of inlet ethanol concentration and UVA-LEDs modules number on ethanol conversion, acetaldehyde concentration, and apparent quantum yield.

\begin{tabular}{lcccccc}
\hline $\begin{array}{l}\text { UVA-LEDs } \\
\text { modules } \\
\text { number }\end{array}$ & $\begin{array}{c}\text { Inlet ethanol } \\
\text { concentration vol. } \\
\%\end{array}$ & $\begin{array}{c}\text { Ethanol } \\
\text { conversion } \%\end{array}$ & $\begin{array}{c}\text { Acetaldehyde } \\
\text { concentration ppm }\end{array}$ & $\begin{array}{c}\text { Incident light } \\
\text { intensity mW/cm }{ }^{2}\end{array}$ & $\begin{array}{c}\text { Irradiated } \\
\text { window } \mathrm{cm}^{2}\end{array}$ & $\begin{array}{c}\text { Apparent quantum } \\
\text { yield \% }\end{array}$ \\
\hline 2 & 0.2 & 73 & 1416 & 90 & 40 & 8.2 \\
2 & 1 & 27 & 2592 & 90 & 40 & 15.2 \\
4 & 0.2 & 100 & 1940 & 90 & 80 & 5.6 \\
4 & 1 & 57 & 5472 & 90 & 80 & 16.1 \\
\hline
\end{tabular}

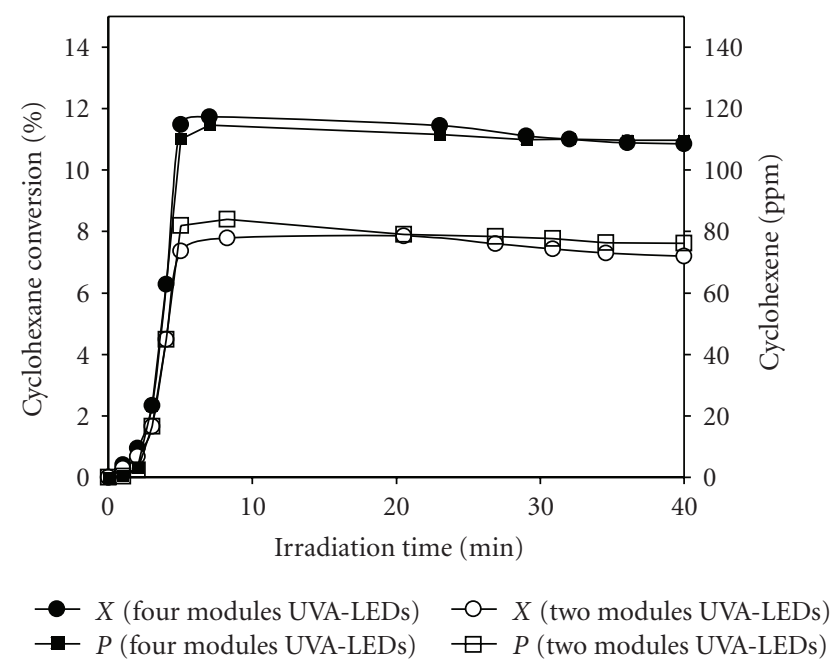

Figure 7: Cyclohexane conversion $(X)$ and cyclohexene concentration $(P)$ as a function of irradiation time; temperature: $120^{\circ} \mathrm{C}$; light intensity: $90 \mathrm{~mW} / \mathrm{cm}^{2}$; catalyst: $8 \mathrm{Mo} 2 \mathrm{~S}$.

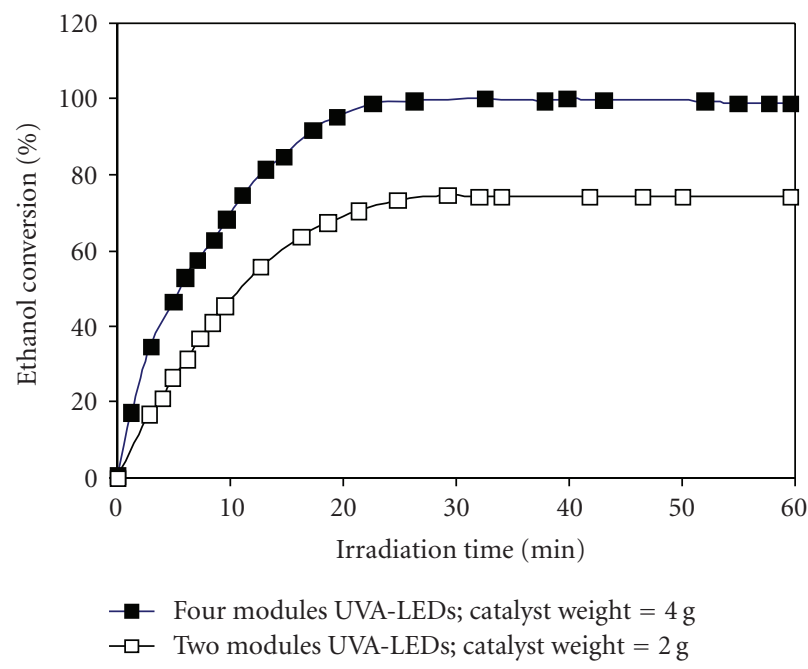

FIGURE 8: Ethanol conversion as function of irradiation time; initial ethanol concentration: $0.2 \mathrm{vol} \% \%$; reaction temperature: $100^{\circ} \mathrm{C}$; light intensity: $90 \mathrm{~mW} / \mathrm{cm}^{2}$; catalyst: $5 \mathrm{~V}$.

Similar selectivity values to acetaldehyde (96\%-97\%) were obtained for both values of ethanol concentration and

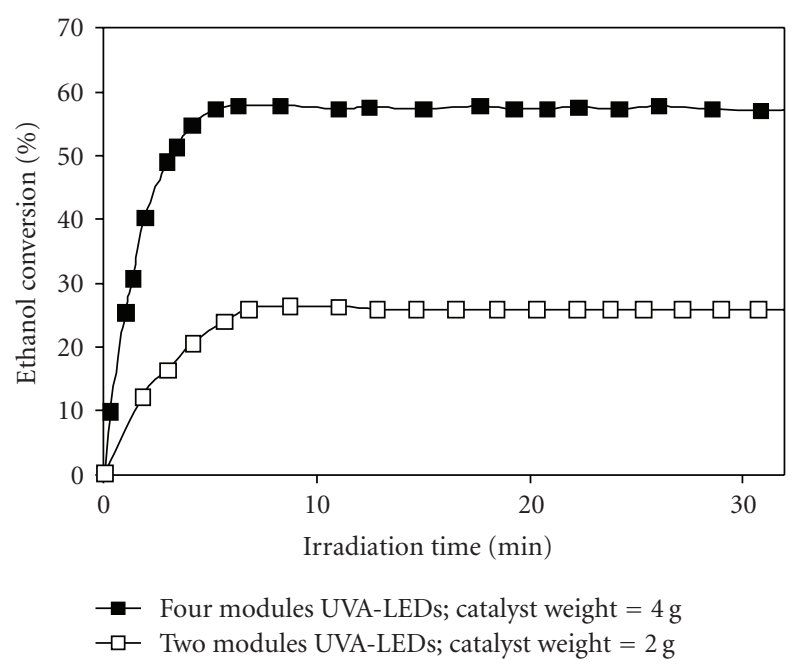

FIGURE 9: Ethanol conversion as function of irradiation time; initial ethanol concentration: 1 vol. \%; reaction temperature: $100^{\circ} \mathrm{C}$; light intensity: $90 \mathrm{~mW} / \mathrm{cm}^{2}$; catalyst: $5 \mathrm{~V}$.

only $\mathrm{CO}_{2}$ and ethylene were detected as by-products. Both ethanol conversion and products concentrations (Figures 8 and 9) remained unchanged during the irradiation time ( $\sim 60$ minutes). The dependence of ethanol conversion from catalyst weight and irradiation configuration at 0.2 and 1 vol. \% inlet concentration are shown in Figures 8 and 9, respectively.

The comparison of the photocatalytic performances with two modules of UVA-LEDs and $2 \mathrm{~g}$ catalyst weight shows that ethanol conversion decreases from $73 \%$ to $27 \%$ by increasing ethanol initial concentration from 0.2 to 1 vol. \%, with small differences in products selectivity.

However, this corresponds to an increase of acetaldehyde concentration from 1416 to 2592 ppm (Table 3). Similarly, with four modules of UVA-LEDs and $4 \mathrm{~g}$ catalyst weight ethanol conversion was complete with 0.2 vol. $\%$ alcohol initial concentration and reached about $57 \%$ with 1 vol. \%, giving up to $5472 \mathrm{ppm}$ of acetaldehyde outlet concentration without variation in products selectivity. Apparent quantum yield increased by increasing ethanol inlet concentration (Table 3) reaching higher values than usually reported [19, 20]. At high ethanol initial concentration quite similar values of apparent quantum yield were found with two and four UVA-LEDs modules. 


\section{Conclusions}

In this work the photocatalytic performances of a twodimensional fluidized bed reactor illuminated by traditional UV lamps and by a microscale illumination system based on UVA-LEDs have been compared for the oxidative dehydrogenation of cyclohexane to benzene as probe reaction.

By irradiating the fluidized bed reactor by UVA-LEDs higher photoactivity was achieved with $\mathrm{MoO}_{\mathrm{x}} / \mathrm{TiO}_{2}-\mathrm{Al}_{2} \mathrm{O}_{3}$ catalyst in similar operating conditions than with UV lamps. The microscale illumination system based on UVALEDs allowed overcoming photon transfer limitations. Better performances in terms of catalyst illumination were likely due to the special geometry of UV-LEDs that avoids photons dispersion and long optical paths. Moreover, the UVLEDs-fluidized bed photoreactor has smaller dimension and higher safety and does not need any deflectors. Microscale illumination is very effective also in different synthesis reactions such as phototocatalytic oxidative dehydrogenation of cyclohexane to cyclohexene on fludizable sulphated $\mathrm{MoO}_{\mathrm{x}} / \gamma$ $\mathrm{Al}_{2} \mathrm{O}_{3}$ and ethanol to acetaldehyde on $\mathrm{VO}_{\mathrm{x}} / \mathrm{TiO}_{2}$.

\section{Acknowledgment}

The authors thank Millenium Inorganic Chemicals for providing titania samples used in this work.

\section{References}

[1] C. B. Almquist and P. Biswas, "The photo-oxidation of cyclohexane on titanium dioxide: an investigation of competitive adsorption and its effects on product formation and selectivity," Applied Catalysis A, vol. 214, no. 2, pp. 259-271, 2001.

[2] T. Van Gerven, G. Mul, J. Moulijn, and A. Stankiewicz, "A review of intensification of photocatalytic processes," Chemical Engineering and Processing, vol. 46, no. 9, pp. 781789, 2007.

[3] D. D. Dionysiou, G. Balasubramanian, M. T. Suidan, A. P. Khodadoust, I. Baudin, and J.-M. Laîné, "Rotating disk photocatalytic reactor: development, characterization, and evaluation for the destruction of organic pollutants in water," Water Research, vol. 34, no. 11, pp. 2927-2940, 2000.

[4] H. C. Yatmaz, C. Wallis, and C. R. Howarth, "The spinning disc reactor-studies on a novel $\mathrm{TiO}_{2}$ photocatalytic reactor," Chemosphere, vol. 42, no. 4, pp. 397-403, 2001.

[5] H. Lin and K. T. Valsaraj, "Development of an optical fiber monolith reactor for photocatalytic wastewater treatment," Journal of Applied Electrochemistry, vol. 35, no. 7-8, pp. 699708,2005

[6] H. Lu, M. A. Schmidt, and K. F. Jensen, "Photochemical reactions and on-line UV detection in microfabricated reactors," Lab on a Chip, vol. 1, no. 1, pp. 22-28, 2001.

[7] T. H. Lim, S. M. Jeong, S. D. Kim, and J. Gyenis, "Photocatalytic decomposition of $\mathrm{NO}$ by $\mathrm{TiO}_{2}$ particles," Journal of Photochemistry and Photobiology A, vol. 134, no. 3, pp. 209217, 2000.

[8] P. Ciambelli, V. Palma, D. Sannino, S. Vaccaro, and V. Vaiano, "Selective oxidation of cyclohexane to benzene on molybdena-titania catalysts in fluidized bed photocatalytic reactor," Studies in Surface Science and Catalysis, vol. 172, p. 453, 2007.

[9] P. Ciambelli, D. Sannino, V. Palma, et al., "Tuning the selectivity of $\mathrm{MoO}_{x}$ supported catalysts for cyclohexane photo oxidehydrogenation," Catalysis Today, vol. 128, no. 3-4, pp. 251-257, 2007.

[10] P. Ciambelli, D. Sannino, V. Palma, et al., "Photocatalytic cyclohexane oxidehydrogenation on sulphated $\mathrm{MoO}_{\mathrm{x}} / \gamma-$ $\mathrm{Al}_{2} \mathrm{O}_{3}$ catalysts," Catalysis Today, vol. 141, no. 3-4, pp. 367373, 2009.

[11] P. Ciambelli, D. Sannino, V. Palma, and V. Vaiano, "The effect of sulphate doping on nanosized $\mathrm{TiO}_{2}$ and $\mathrm{MoO}_{\mathrm{x}} / \mathrm{TiO}_{2}$ catalysts in cyclohexane photooxidative dehydrogenation," International Journal of Photoenergy, vol. 2008, Article ID 258631, 8 pages, 2008.

[12] R. Gorges, S. Meyer, and G. Kreisel, "Photocatalysis in microreactors," Journal of Photochemistry and Photobiology A, vol. 167, no. 2-3, pp. 95-99, 2004.

[13] D. H. Chen, X. Ye, and K. Li, "Oxidation of PCE with a UV LED photocatalytic reactor," Chemical Engineering and Technology, vol. 28, no. 1, pp. 95-97, 2005.

[14] P. Ciambelli, D. Sannino, V. Palma, and V. Vaiano, "Fotoreattore catalitico ad alta efficienza di illuminazione per processi intensificati di fotossidazione," Italian patent pending SAA2008000012.

[15] H.-W. Chen, Y. Ku, and A. Irawan, "Photodecomposition of o-cresol by UV-LED/TiO 2 process with controlled periodic illumination," Chemosphere, vol. 69, no. 2, pp. 184-190, 2007.

[16] P. Ciambelli, D. Sannino, V. Palma, and V. Vaiano, "Improved photocatalytic synthesis of benzene by oxidative dehydrogenation of cyclohexane on $\mathrm{MoO}_{\mathrm{x}} / \mathrm{TiO}_{2}-\mathrm{Al}_{2} \mathrm{O}_{3}$ catalysts,"Chemical Engineering Transactions, vol. 11, p. 971, 2007.

[17] P. Ciambelli, D. Sannino, V. Palma, V. Vaiano, and R. S. Mazzei, "A step forwards in ethanol selective photo-oxidation," Photochemical and Photobiological Sciences, vol. 8, no. 5, pp. 699704, 2009.

[18] V. Vaiano, "Heterogeneous photocatalytic selective oxidation of cyclohexane," Ph.D. thesis, University of Salerno, Salerno, Italy, March 2006.

[19] A. V. Vorontsov, E. N. Savinov, G. B. Barannik, V. N. Troitsky, and V. N. Parmon, "Quantitative studies on the heterogeneous gas-phase photooxidation of CO and simple VOCs by air over $\mathrm{TiO}_{2}$," Catalysis Today, vol. 39, no. 3, pp. 207-218, 1997.

[20] P. Du, J. A. Moulijn, and G. Mul, "Selective photo(catalytic)oxidation of cyclohexane: effect of wavelength and $\mathrm{TiO}_{2}$ structure on product yields," Journal of Catalysis, vol. 238, no. 2, pp. 342-352, 2006. 


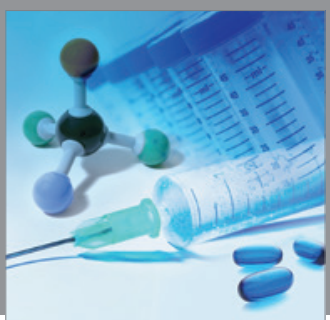

International Journal of

Medicinal Chemistry

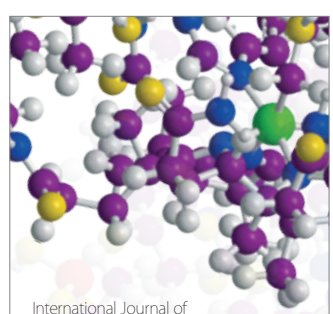

Carbohydrate Chemistry

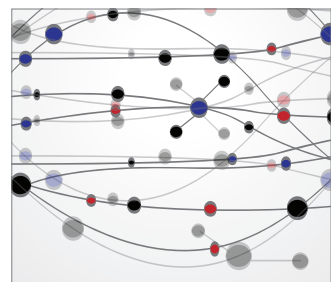

The Scientific World Journal
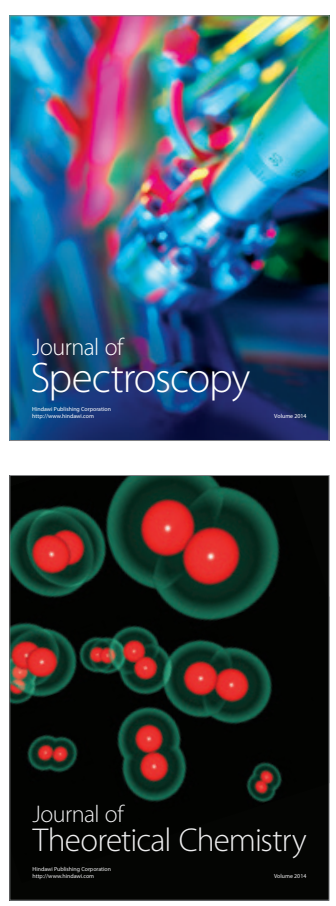
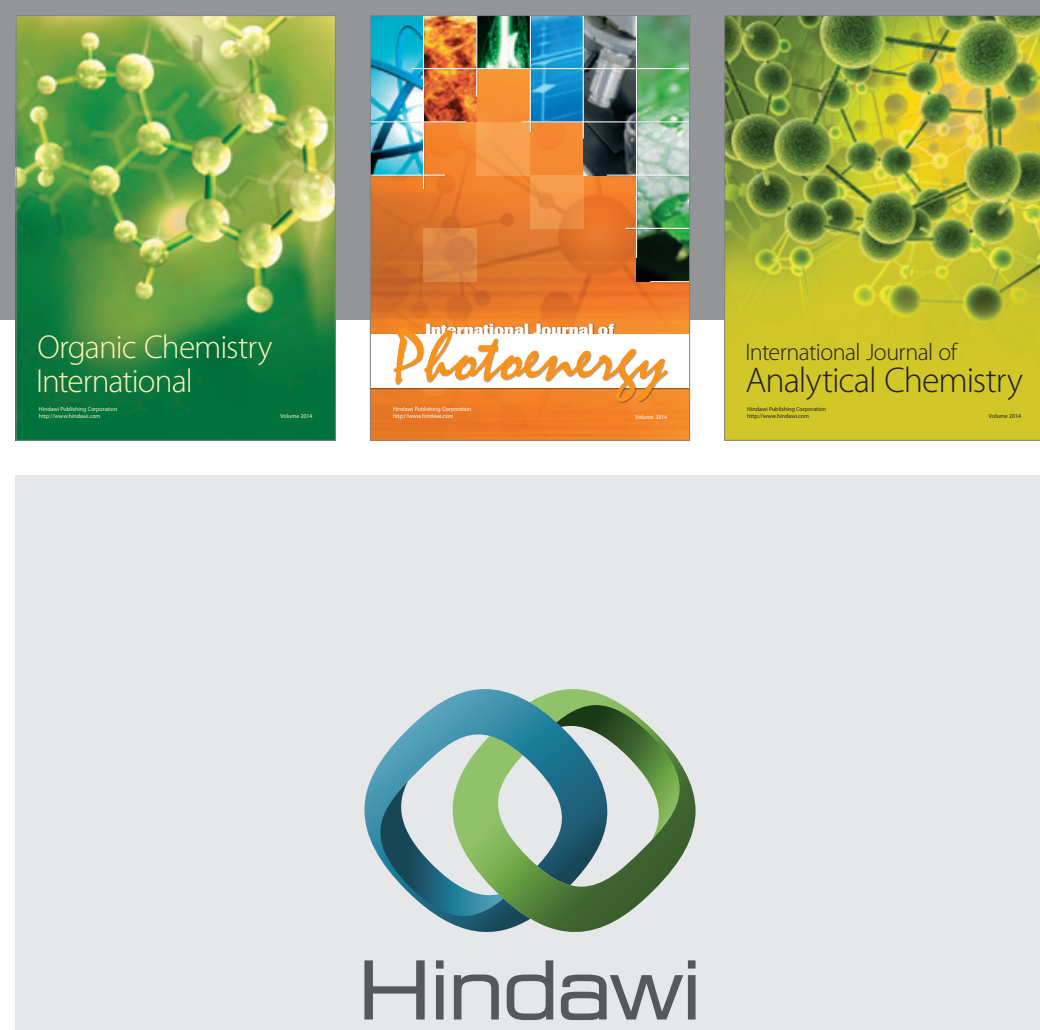

Submit your manuscripts at

http://www.hindawi.com
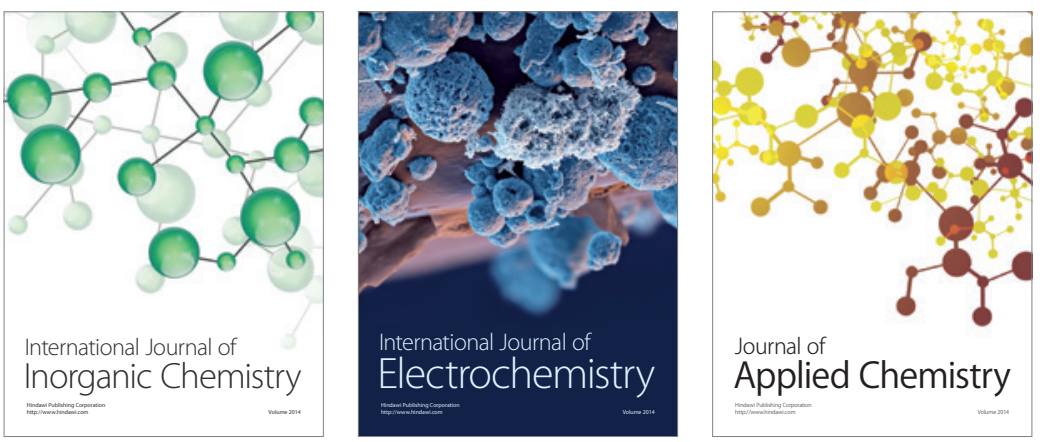

Journal of

Applied Chemistry
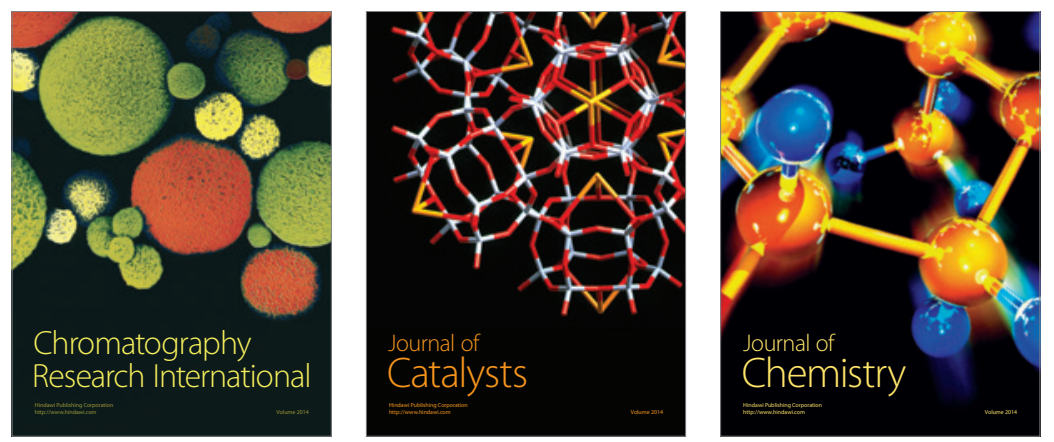
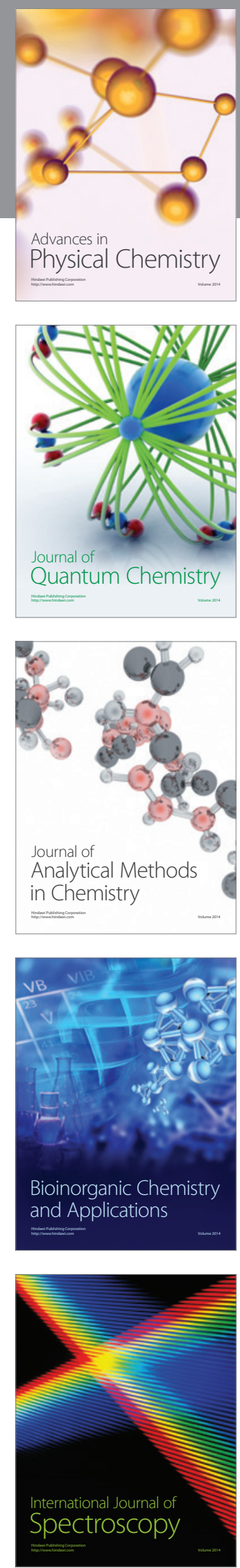